\title{
Updated ozone absorption cross section will reduce air quality compliance
}

\author{
E. D. Sofen ${ }^{1}$, M. J. Evans ${ }^{1,2}$, and A. C. Lewis ${ }^{1,2}$ \\ ${ }^{1}$ Wolfson Atmospheric Chemistry Laboratories, Department of Chemistry, University of York, York, YO10 5DD, UK \\ ${ }^{2}$ National Centre for Atmospheric Science, Department of Chemistry, University of York, York, YO10 5DD, UK \\ Correspondence to: E. D. Sofen (esofen@gmail.com)
}

Received: 24 June 2015 - Published in Atmos. Chem. Phys. Discuss.: 17 July 2015

Revised: 10 November 2015 - Accepted: 30 November 2015 - Published: 10 December 2015

\begin{abstract}
Photometric ozone measurements rely upon an accurate value of the ozone absorption cross section at $253.65 \mathrm{~nm}$. This has recently been re-evaluated by Viallon et al. (2015) as $1.8 \%$ smaller than the accepted value (Hearn, 1961) used for the preceding 50 years. Thus, ozone measurements that applied the older cross section systematically underestimate the amount of ozone in air. We correct the reported historical surface data from North America and Europe and find that this modest change in cross section has a significant impact on the number of locations that are out of compliance with air quality regulations if the air quality standards remain the same. We find 18, 23, and $20 \%$ increases in the number of sites that are out of compliance with current US, Canadian, and European ozone air quality health standards for the year 2012. Should the new cross-section value be applied, it would impact attainment of air quality standards and compliance with relevant clean air acts, unless the air quality target values themselves were also changed proportionately. We draw attention to how a small change in gas metrology has a global impact on attainment and compliance with legal air quality standards. We suggest that further laboratory work to evaluate the new cross section is needed and suggest three possible technical and policy responses should the new cross section be adopted.
\end{abstract}

\section{Introduction}

Surface ozone is a significant global air pollutant that is detrimental to human health, crops, and natural ecosystems through its oxidative damage to respiratory systems and the leaves of plants (National Research Council, 2008; McDon- nell et al., 1993; Bell et al., 2004; Bell and Treshow, 2002; Lefohn and Runeckles, 1987). In order to reduce human exposure to ozone pollution, various legislative frameworks have been put in place by environmental agencies around the world. The United States, Canada, and the European Union all maintain air quality regulations that determine compliance based on exceedances of a threshold value of maximum daily $8 \mathrm{~h}$ average (MDA8) ozone on an annual basis averaged over 3 years. The standards and corresponding monitoring networks for the United States, Canada, and the EU are described in Table 1.

The abundance of ozone near the Earth's surface has been intermittently measured since the late $1800 \mathrm{~s}$ (Volz and Kley, 1988; Marenco et al., 1994; Pavelin et al., 1999). In the 1970s, North American and European nations began to develop systematic networks for the continuous monitoring of the concentration of surface ozone in a range of environments (roadside, urban, suburban, rural, remote) for the purposes of air quality monitoring and regulation. Concerted regulatory efforts to reduce ozone precursors have resulted in a decline in peak ozone concentrations in both the United States and the EU over the past decade (Cooper et al., 2014; Rieder et al., 2013).

There are a range of techniques to measure ozone (Parrish and Fehsenfeld, 2000). However, the vast majority of ozone measurements, especially for regulatory monitoring, are made using dual-cell ultraviolet (UV) absorption spectrophotometers such as the Thermo Environmental Instruments Inc. Model 49 or 2B Technologies, Inc. Model 202. Fundamentally, this approach relies upon the Beer-Lambert law with the critical parameters being the length of the cell, the absorption cross section of ozone at $253.65 \mathrm{~nm}$, and the 
Table 1. Ozone air quality standards and monitoring networks.

\begin{tabular}{|c|c|c|}
\hline Entity & Air quality standard & Monitoring network and data source \\
\hline European Union & $\begin{array}{l}\text { Non-attainment if there are more than } \\
25 \text { days year }{ }^{-1} \text { in which the maximum daily } \\
8 \mathrm{~h} \text { average (MDA8) ozone concentration } \\
\text { exceeds } 120 \mu \mathrm{g} \mathrm{m}^{-3} \text {, averaged over } 3 \text { years } \\
\text { (EEA, 2002). }\end{array}$ & $\begin{array}{l}\text { European Environment Agency AirBase; } \\
\text { http://www.eea.europa.eu/data-and-maps/data/ } \\
\text { airbase-the-european-air-quality-database- } 8\end{array}$ \\
\hline United States & $\begin{array}{l}\text { Non-attainment if the annual fourth-highest } \\
\text { ozone MDA } 8 \text { mixing ratio averaged over } 3 \\
\text { years is above } 75 \text { ppbv (EPA, 2008). }\end{array}$ & $\begin{array}{l}\text { Environmental Protection Agency Air Qual- } \\
\text { ity System (EPA AQS); http://www.epa.gov/ } \\
\text { airquality/airdata/ad_data.html }\end{array}$ \\
\hline Canada & $\begin{array}{l}\text { Non-attainment if the annual fourth-highest } \\
\text { MDA8 ozone mixing ratio averaged over } 3 \\
\text { years is above } 63 \text { ppbv (CAN, 2012). }\end{array}$ & $\begin{array}{l}\text { Environment Canada National Air Pollu- } \\
\text { tion Surveillance Program (NAPS); http:// } \\
\text { maps-cartes.ec.gc.ca/rnspa-naps/data.aspx }\end{array}$ \\
\hline
\end{tabular}

ozone concentration. Historically, the ozone cross section used for surface observations and the standard reference photometer has been $11.476 \times 10^{-18} \mathrm{~cm}^{2}$ molecule ${ }^{-1}$ based on the work of Hearn (1961). This has allowed for the systematic measurement of the ozone. New instruments, such as those manufactured by 2B Technologies, Inc., also use the Hearn (1961) cross section.

Despite the wide use of these absorption techniques for the measurement of ozone, they are only as accurate as the fundamental physical parameters used in the conversion of absorption to concentration. Recent re-measurement of the absorption cross sections by Viallon et al. (2015) find a cross section of $(11.27 \pm 0.097) \times 10^{-18} \mathrm{~cm}^{2}$ molecule ${ }^{-1}$ (mean $\pm 2 \sigma$ ) that is $1.8 \%$ lower than the Hearn (1961) evaluation. If the Viallon et al. (2015) absorption cross section is officially adopted, this will imply that the ozone observations in ambient air are systematically $1.8 \%$ higher than previously reported.

Figure 1 illustrates all available ozone absorption cross sections at $253.65 \mathrm{~nm}$ and their uncertainties based on a compilation by Orphal (2002). The absorption cross sections measured by Hearn (1961) (maroon) and Viallon et al. (2015) (grey) are highlighted with thick lines. Most cross sections are lower than that reported by Hearn (1961). The Viallon et al. (2015) cross section is the lowest of all of the reported values.

This $1.8 \%$ change in the ozone absorption cross section appears to be modest. However, the pass/fail nature of air quality standards and the reality that many sites are just below an air quality standard threshold means that a modest increase in ozone has the potential to place many sites over the limit and force them out of compliance with the appropriate legislation.

In this work, we explore the impact of the new ozone cross-section value and the impact of a historical underestimate of ozone on compliance with air quality regulations. We use US, Canadian, and European ozone monitoring data and evaluate the number of sites that are out of compliance with

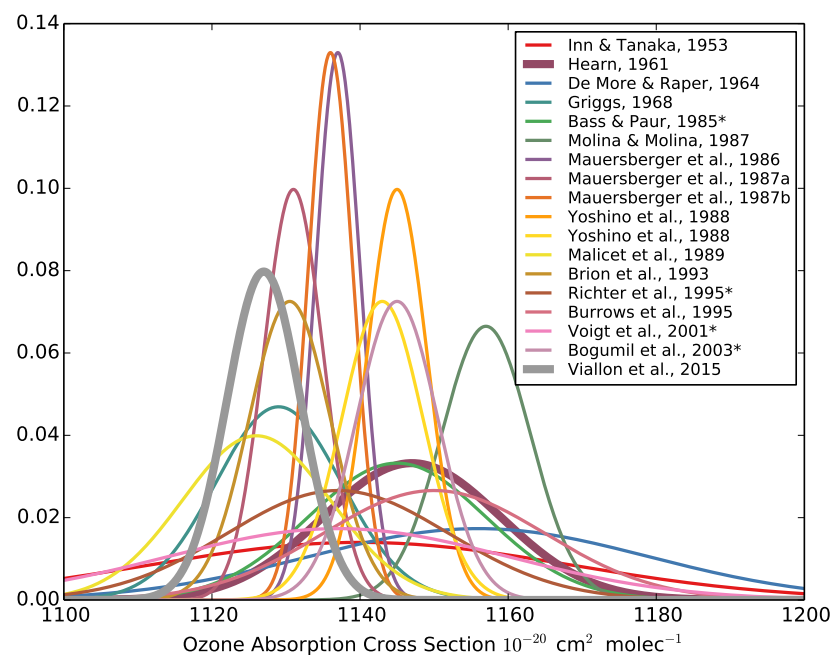

Figure 1. Compilation of ozone absorption cross sections and their uncertainty based on Orphal (2002). Absorption cross sections marked with a $\left(^{*}\right)$ are relative measurements scaled based on calibration.

the current cross section. We then repeat the evaluation of the same metrics with the $(1.8 \pm 0.9) \%$ increase in ozone concentration and evaluate the impact. Finally, we also consider the need to reprocess the historical data sets so that trends can be appropriately calculated.

\section{Ozone observations}

We use the publicly available air quality monitoring data sets from the US Environmental Protection Agency Air Quality System (EPA AQS), Environment Canada's National Air Pollution Surveillance Program (NAPS), and the European Environment Agency (EEA) AirBase. The EPA AQS represents data collected for the enforcement of the US Clean Air Act and consists of ozone measurements from up to 
2326 sites. NAPS is a similar network for Canada that is made up of 369 sites. The EU AirBase is a composite database made up of air quality data contributed by $40 \mathrm{Eu}-$ ropean member states with a total of 3524 sites that measure ozone. The vast majority of observations are made using UV absorption instruments, with a very small subset using other methods such as chemiluminescence. Out of 2326 EPA sites that have reported ozone, only 52 have used chemiluminescence at some point since 1993. None are used in 2012. Eight of the 3524 AirBase sites use chemiluminescence in 2012. For each data set, we calculate whether or not a site is in compliance with the relevant air quality standard for each year (Table 1). According to the definitions of all three standards, this represents an average over the 3 years; that is, the 2012 determination averages over 2010-2012. Our calculations may differ slightly from official governmental air quality exceedance tallies due to differences in quality control, data processing, data completeness thresholds, rounding, and legislative changes in air quality threshold values over time. We adopt a conservative approach of requiring data for all years included in the 3-year rolling average. We do not attempt to reproduce the detailed regulatory algorithms used by the 42 countries considered in this analysis.

\section{Results and discussion}

\subsection{Air quality violations with the Hearn (1961) cross section}

We apply here US, Canadian, and EU ozone air quality exceedance calculations to their respective data sets using the mixing ratios/concentrations as provided (e.g. using the Hearn, 1961, cross section). Figure 2 shows the locations of the data sets that fail to comply with these metrics in North America and Europe in pink for 2012. Applicable air quality thresholds are exceeded at 179 EPA AQS sites, 30 Canadian NAPS sites, and 215 EU AirBase sites. Based on visual inspection, the map of US exceedances agrees well with the current EPA non-attainment areas (EPA, 2015b, a), although the comparison is complicated by the county-level determinations of non-attainment areas done by the EPA, and probable issues related to the rounding of concentration values (EPA, 2008). The European exceedances show near perfect agreement with official European Environment Agency maps (Map 2.3) (EEA, 2013), with slight differences through Spain and the Balkans likely due to either the summertime focus of the EEA calculation or different data completeness thresholds.

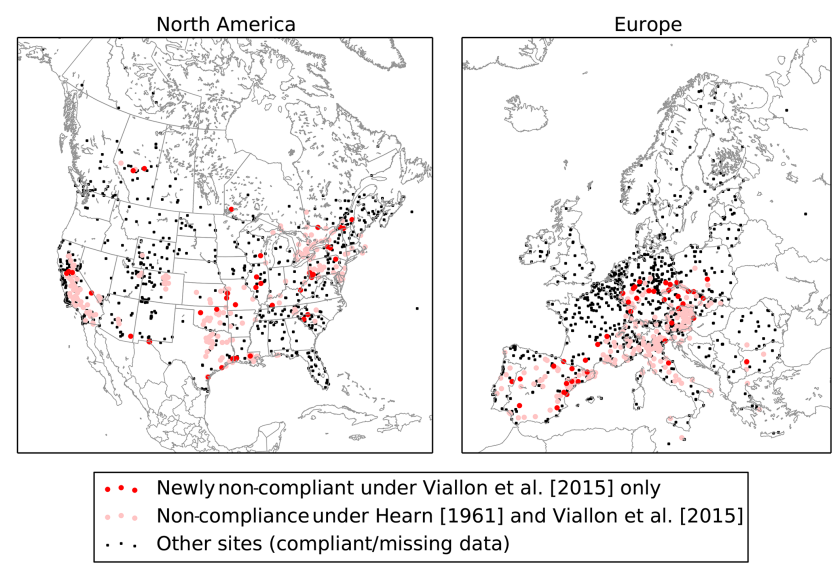

Figure 2. Ozone monitoring sites that are out of compliance with US, Canadian, or EU air quality standards. Pink markers indicate sites that are out of compliance using the current Hearn (1961) absorption cross section. These sites are also out of compliance when the data are increased by $1.8 \%$ to account for the new Viallon et al. (2015) cross section. Red markers indicate the additional sites that become out of compliance if the Viallon et al. cross section is applied. Black points indicate sites that are in compliance or are missing data so that compliance cannot be calculated.

\subsection{Air quality violations with Viallon et al. (2015) cross section}

We now repeat the previous assessment but increase the ozone concentrations by $1.8 \%$ to reflect the absorption in new cross sections from Viallon et al. (2015). The red markers in Fig. 2 show the locations of additional sites in 2012, which would violate the air quality standard with the Viallon et al. (2015) cross section that did not violate the standards under the older Hearn (1961) cross section. There are an additional 33 US EPA sites, 7 Canadian NAPS sites, and 42 EU AirBase sites that exceed prevailing air quality standards solely due to the adjustment in the absorption cross section. This corresponds to a fractional increase of 18, 23, and $20 \%$ in US, Canadian, and European exceedances, respectively.

The new air quality exceedances tend to be located around the periphery of regions that are already out of compliance with the air quality standards. However, in North America, a number of new air quality exceedances appear in northern New England, Illinois, and South Carolina unconnected to existing regions of exceedance.

As shown in Fig. 3, depending on the year, there are up to an additional $25 \%$ of sites that exceed their air quality standard simply due to the adjusted concentrations using the new Viallon et al. (2015) cross section. We calculate the uncertainty in the fractional increase based on the propagation of the $2 \sigma$ uncertainty in the Viallon et al. (2015) absorption cross section. A greater fraction of additional sites fall out of compliance under the Viallon et al. (2015) cross section in recent years (e.g. 2008-2012) than in earlier years (e.g. 1990- 


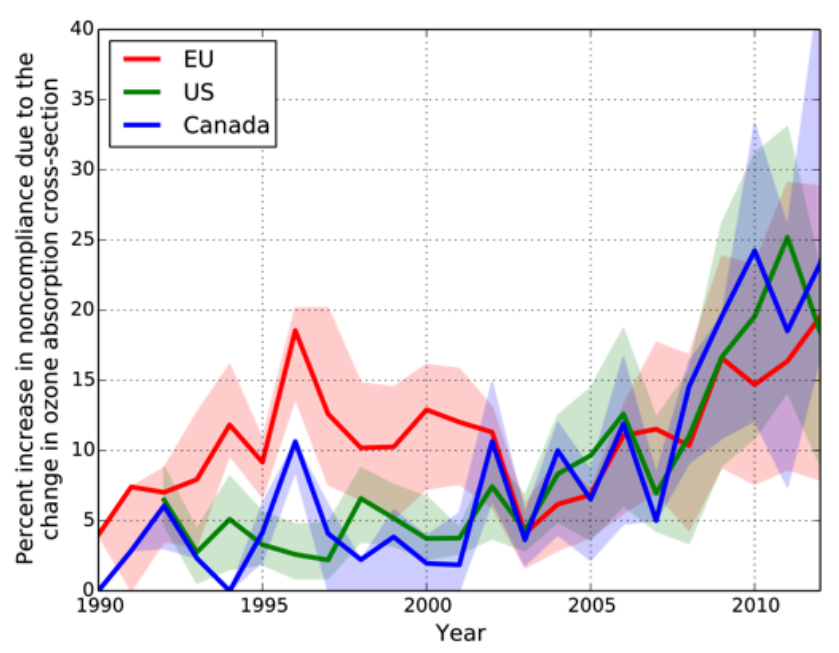

Figure 3. The percent increase in the number of sites that are out of compliance with air quality regulations due to the adjusted ozone abundances suggested by the new Viallon et al. (2015) cross section for the EU, the United States, and Canada between 1990 and 2012. Shaded regions indicate the uncertainty in the number of noncompliant sites associated with the 2 standard deviation uncertainty in the Viallon et al. cross section.

2000), because there are a greater number of sites in more recent years that have become compliant with the current regulatory standards under the Hearn (1961) cross section but that are still very near the threshold. This is in part due to the tightening of ozone regulatory standards over this time period, meaning that in the earlier time period, more sites were out of compliance with current regulatory standards, whereas in recent years they sit just below the regulatory threshold, making them susceptible to exceedance with the $1.8 \%$ increase in ozone. Though the regulatory standards in the EU and North America are calculated differently, the changes in both regions are very similar.

While the re-evaluation of the absorption cross section of ozone by Viallon et al. (2015) does mean that ozone concentrations were higher than previously thought, we note that ozone exposure and human health impact studies also relied on measurements made using the Hearn (1961) cross section. Therefore, there is no inherent inconsistency between the regulatory standards set for health purposes, or ecosystem metrics such as AOT40 (accumulated amount of ozone over $40 \mathrm{ppb}$ during daytime in the growing season), and the concentration/mixing-ratio values from ozone monitoring using the Hearn (1961) cross section. However, given the tendency of legislative and regulatory bodies to adjust standards in roughly $5 \mathrm{ppbv} / 10 \mu \mathrm{g} \mathrm{m}^{-3}$ increments, it is worth noting that much smaller changes in the reported concentration of ozone can have significant implications for air quality regulation.

The $2 \sigma$ uncertainty in the absorption cross section of $\pm 0.9 \%$ contributes to an uncertainty of approximately $\pm 15 \%$ in the increase in sites in non-compliance due to the change in the absorption cross section, as shown in Fig. 3. Further metrological work to reduce the uncertainty in, and indeed to confirm, the Viallon et al. (2015) absorption cross section may be needed. If the fractional uncertainty in the absorption cross section is reduced to $\pm 0.1 \%$, this reduces the uncertainty in compliance to less than $\pm 3 \%$. Reducing the uncertainty in the absorption cross section will represent a major analytical challenge, with the largest sources of uncertainty coming from the absorption cell path length, ozone mole fraction uncertainties, and pressure measurements (Viallon et al., 2015). Equivalently, there would be at most four AirBase sites, whose compliance status would be uncertain if the fractional uncertainty on the absorption cross section were reduced to $\pm 0.1 \%$. There are numerous other sources of uncertainty in ozone measurements (Klausen et al., 2003; Wilson and Birks, 2006) but they generally represent random errors, whereas updates to the absorption cross section represent correction of a systematic bias.

The widespread use of ozone photometric measurements in atmospheric chemistry is likely to require also some adjustments to laboratory kinetic data for ozone reactions. Observations of species such as hydroxyl radicals, that rely on known ozone amounts for calibration, will also require adjustment. In many cases the adjustment is however likely to be within existing measurement uncertainties.

\subsection{Future adoption of the Viallon et al. (2015) cross section}

Given a potential change in the accepted cross section (something that would ultimately require a recommendation from the International Union of Physical and Applied Chemistry, IUPAC), regulatory agencies, global monitoring entities, and instrument manufacturers will need to make decisions about how future observations are made and how historic data are reprocessed. In practical terms, formally updating the absorption cross section in existing instruments is not straightforward, typically requiring an update to firmware within the instrument. However, a potential workaround for users would be a one-off modification of the calibration slope "span" parameters to reflect a $1.8 \%$ change through the instrument calibration software interface. The inclusion of updated parameters would also occur when new instruments are installed (assuming manufacturers opt to use the Viallon et al., 2015, cross section). A typical lifespan for an ozone instrument in use for operational air quality monitoring is around 10 years, which would result in a slow increment in updated values entering the global data set. In both cases it would be essential that such changes, whether to existing instruments or to new ones, are robustly recorded within metadata submissions that accompany observational data. In both cases it would be difficult to detect the change independently using step-change 
statistical methods, but it would lead to a small spurious positive trend.

\section{Conclusions: policy options}

If proven correct, the application of an updated value for the ozone cross section at $253.65 \mathrm{~nm}$ leads to a significant (10$25 \%$ ) increase in the number of sites in North America and Europe that become non-compliant with local air quality regulations. Such an increase is very significant in the context of pollution control and the legal attainment of national air quality targets, and it is highly likely that substantial policy and technical responses will be required globally. We consider that there are three broad possible scenarios that may be adopted to reflect an updated ozone cross-section value.

- Continue to use the Hearn (1961) value for surface ozone monitoring and air quality limit values. Only adopt the Viallon et al. (2015) value when the reporting of the absolute amount of ozone is essential, such as when ozone is included in radiative forcing calculations. This would move the observation of surface ozone away from traceability from an SI (International System of Units - Système International d'Unités) amount of substance to a measurement scale.

- Adopt the updated cross-section values within national and global ozone measurement networks, while maintaining current air quality standards. Such a policy would effectively amount to a $1.8 \%$ tightening in national air quality standards and an increase in regulatory non-compliance. There are potentially costly legal ramifications for regulatory agencies when additional sites are pushed into non-compliance because of this "moving of the goalposts."

- Adopt the updated cross-section values within measurement networks and change the air quality standards by the same proportion. This will maintain the same level of air quality attainment. Such an approach would almost certainly require legislative changes in many countries, something that might potentially be subsumed within a larger-limit value change, for example at the 5 ppbv or $\mu \mathrm{g} \mathrm{m}^{-3}$ unit increment.

A concerted effort to re-measure the cross section and provide confirming evidence is needed. However, if the new Viallon et al. (2015) absorption cross section is ultimately adopted for new instruments, there would be a significant issue for air quality compliance. A decision on the best path forward for the sake of air quality and human health, ozone research, and policy must be addressed by a combination of air quality scientists, data managers, and policy makers.

We also identify the importance of adopting a globally consistent approach in the analysis of trends in surface ozone. Unless a common re-evaluation is made of the historical data set, such as in global background data collected as part of WMO Global Atmosphere watch, a discontinuity will be introduced into the record, which will appear as a spurious positive trend.

The substantial impact on air quality policy of this modest change to the ozone absorption cross section reinforces the importance of fundamental metrology research and suggests a need to re-evaluate the values of many decades-old physicochemical constants.

Acknowledgements. We acknowledge funding from NERC grant NE/K016008/1 and NE/L01291X/1.

Edited by: S. Brown

\section{References}

Bell, J. N. B. and Treshow, M. (Eds.): Air Pollution and Plant Life, 2nd Edn., John Wiley \& Sons Ltd., Chichester, UK, 2002.

Bell, M. L., McDermott, A., Zeger, S. L., Samet, J. M., and Dominici, F.: Ozone and short-term mortality in 95 US urban communities, 1987-2000, JAMA-J. Am. Med. Assoc., 292, 23722378, doi:10.1001/jama.292.19.2372, 2004.

CAN (Canadian Council of Ministers of the Environment): Guidance Document on the Achievement Determination Canadian Ambient Air Quality Standards for Fine Particulate Matter and Ozone, Canadian Council of Ministers of the Environment, Winnipeg, Manitoba, Canada, 2012.

Cooper, O., Parrish, D. D., Ziemke, J., Balashov, N. V., Cupeiro, M. Galbally, I. E., Gilge, S., Horowitz, L., Jensen, N. R., Lamarque, J.-F., Naik, V., Oltmans, S. J., Schwab, J., Shindell, D. T., Thompson, A. M., Thouret, V., Wang, Y., and Zbinden, R. M.: Global distribution and trends of tropospheric ozone: an observation-based review, Elementa: Science of the Anthropocene, 2, 000029, doi:10.12952/journal.elementa.000029, 2014.

EEA (European Environment Agency): Directive 2002/3/EC of the European Parliament and of the Council of 12 February 2002 relating to ozone in ambient air, in: Official Journal of the European Communities, Luxembourg, p. L67/14, 2002.

EEA (European Environment Agency): Air Pollution by Ozone Across Europe During Summer 2012: Overview of Exceedances of EC Ozone Threshold Values for April-September 2012, Tech. Rep., 3/2013, European Environment Agency, Copenhagen, doi:10.2800/70933, 2013.

EPA (Environmental Protection Agency): National Ambient Air Quality Standards for Ozone; Final Rule, in: Federal Register, Washington, D.C., Vol. 73, p. 16436, 2008.

EPA (Environmental Protection Agency): Approval and Promulgation of Air Quality Implementation Plans; Maryland; Determination of Attainment of the 2008 8-Hour Ozone National Ambient Air Quality Standard for the Baltimore, Maryland Moderate Nonattainment Area, in: Federal Register, Washington, D.C., Vol. 80, 14041-14044, 2015a

EPA (Environmental Protection Agency): 8-Hour Ozone Nonattainment Areas (2008 Standard) in EPA Green Book, available 
at: http://www.epa.gov/airquality/greenbook/map8hr_2008.html (last access: 23 March 2015), 2015b.

Hearn, A. G.: The absorption of ozone in the ultra-violet and visible regions of the spectrum, P. Phys. Soc., 78, 932, 1961.

Klausen, J., Zellweger, C., Buchmann, B., and Hofer, P.: Uncertainty and bias of surface ozone measurements at selected Global Atmosphere Watch sites, J. Geophys. Res., 108, 4622, doi:10.1029/2003JD003710, 2003.

Lefohn, A. S. and Runeckles, V. C.: Establishing standards to protect vegetation - ozone exposure/dose considerations, Atmos. Environ., 21, 561-568, doi:10.1016/0004-6981(87)900382, 1987.

Marenco, A., Goutget, H., Nédélec, P., and Pagés, J.-P.: Evidence of a long-term increase in tropospheric ozone from Pic du Midi data series: consequences: positive radiative forcing, J. Geophys. Res., 99, 16617-16632, doi:10.1029/94JD00021, 1994.

McDonnell, W. F., Muller, K. E., Bromberg, P. A., and Shy, C. M.: Predictors of individual differences in acute response to ozone exposure, Am. Rev. Respir. Dis., 147, 818-825, doi:10.1164/ajrccm/147.4.818, 1993.

National Research Council: Estimating Mortality Risk Reduction and Economic Benefits from Controlling Ozone Air Pollution, The National Academies Press, Washington, DC, 2008.

Orphal, J.: A critical review of the absorption cross-sections of $\mathrm{O}_{3}$ and $\mathrm{NO}_{2}$ in the $240-790 \mathrm{~nm}$ region, part I. Ozone, ESA Technical Note MO-TN-ESA-GO-0302, 2002.
Parrish, D. D. and Fehsenfeld, F. C.: Methods for gas-phase measurements of ozone, ozone precursors and aerosol precursors, Atmos. Environ., 34, 1921-1957, doi:10.1016/S13522310(99)00454-9, 2000.

Pavelin, E. G., Johnson, C. E., Rughooputh, S., and Toumi, R.: Evaluation of pre-industrial surface ozone measurements made using Schönbein's method, Atmos. Environ., 33, 919-929, doi:10.1016/S1352-2310(98)00257-X, 1999.

Rieder, H. E., Fiore, A. M., Polvani, L. M., Lamarque, J.-F., and Fang, Y.: Changes in the frequency and return level of high ozone pollution events over the eastern United States following emission controls, Environ. Res. Lett., 8, 014012, doi:10.1088/17489326/8/1/014012, 2013.

Viallon, J., Lee, S., Moussay, P., Tworek, K., Petersen, M., and Wielgosz, R. I.: Accurate measurements of ozone absorption cross-sections in the Hartley band, Atmos. Meas. Tech., 8, 12451257, doi:10.5194/amt-8-1245-2015, 2015.

Volz, A. and Kley, D.: Evauluation of the Montsouris seris of ozone measurements made in the nineteenth century, Nature, 332, 240 242, doi:10.1038/332240a0, 1988.

Wilson, K. L. and Birks, J. W.: Mechanism and elimination of a water vapor interference in the measurement of ozone by UV absorbance, Environ. Sci. Technol., 40, 6361-6367, doi:10.1021/es052590c, 2006. 